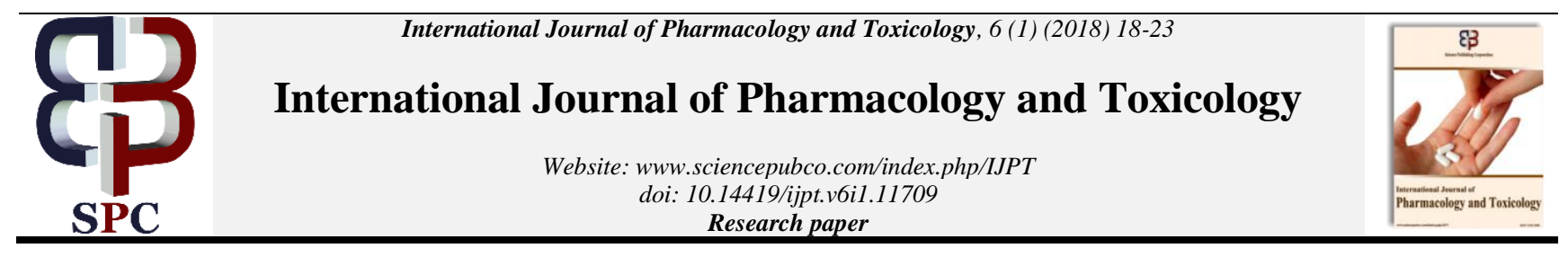

\title{
Effect of azithromycin on fetal development in rats
}

\author{
Ashraf Elkomy ${ }^{1}$, Asmaa M. Kandeil ${ }^{2}$, Mohamed Abo-Salem ${ }^{3}$, Wedad A. Hassan ${ }^{2}$, \\ Mohamed Aboubakr ${ }^{1}$, Alzahraa A. Elhemiely ${ }^{2 *}$ \\ ${ }^{1}$ Department of Pharmacology, Faculty of Veterinary Medicine, Benha University, Egypt \\ ${ }^{2}$ National Organization for Drug Control and Research (NODCAR), Egypt \\ ${ }^{3}$ Department of Forensic Medicine and Toxicology, Faculty of Veterinary Medicine, Benha University, Egypt \\ *Corresponding author E-mail:drzahraa2010@yahoo.com
}

\begin{abstract}
This study was designed to evaluate the potential risks of the Azithromycin administration on fetuses. Therefore pregnant rats were received Azithromycin orally ( 90 and $180 \mathrm{mg} / \mathrm{kg}$ b.wt, daily) from sixth day until the fifteenth day of gestation. At $20^{\text {th }}$ day of gestation female sacrificed; abortion, fetal resorptions, visceral examination, skeletal examination, Oxidative stress markers and histopathological examination for fetuses were recorded. Azithromycin caused abortion, fetal resorptions, growth retardation, hematoma and paralysis of limbs. Also caused cerebral dilatation, microcephaly, perforation of hard palate and hemorrhage around internal organs. By skeletal examination; weak and incomplete ossification were observed in bones .Biochemical studies showed that Azithromycin administration resulted in decreased glutathione reduced but increased malonaldahyde compared to control groups. Fetal kidney revealed degeneration and necrosis in the tubular lining epithelium and fibrosis in between the atrophied renal tubules. This study supports and proofs the potential risks of the azithromycin administration on fetuses.
\end{abstract}

Keywords: Rats, Pregnancy; Macrolides; Azithromycin; Teratology.

\section{Introduction}

Teratogenesisis defined as the dysgenesis of fetal organs, as evidenced either structurally or functionally (e.g. brain functions). The typical manifestations of teratogenesis are restricted growth or death of the fetus, carcinogenesis, and malformations, whichare defined as defects in organ structure or function. Teratology, the study of abnormal prenatal development and congenital malformations induced by exogenous chemical or physical agents, is a growing area of medical research in the quest for the eradication of preventable birth defects (Aboubakr et al., 2014; Elkomy et al., 2016). These malformations may vary in severity with the most severe being life threatening or requiring major surgery (Koren et al., 1998). During pregnancy, treatment of maternal illness with drugs may said to have a beneficial on course of pregnancy. On the other hand, in certain situations, drugs can cause harmful effects on the developing fetus. These harmful effects depend upon the nature of the drug, its doses, the route of administration, the stage of pregnancy at which the drug is given and the genetic constitution and susceptibility of the fetus to the drug (Brent et al., 2007).

Azithromycin is a 15 -membered semisynthetic macrolide antibiotic in the azalide subclass with some structural similarity to erythromycin, but with a prolonged duration of action and improved tissue penetration (Ramsey et al., 2003). Azithromycin has a rapid serum half-life in the term gravid woman with a prolonged half-life and high-sustained antibiotic levels noted within myometrium, adipose, and placental tissue. Given the broad antimicrobial spectrum and placental penetration, azithromycin may have potential use for the treatment of perinatal infections (Ramsey et al., 2003). All macrolides caused haematoma in general, azitromycin caused neural tube defects, maxillary deformity and situs inversus most frequently azitromycin appeared more teratogenic compared with other compounds (Benjamin et al.,2008). The macrolide antibiotics are a structurally similar groupof primarily bacteriostatic compounds (Elsayed et al., 2014). Elective terminations of pregnancy because of early exposure to the new macrolides (clarithromycin, azithromycin, roxithromycin) should be reconsidered (Benjamin et al., 2008). Treatment of young infants with macrolides associated with hypertrophic pyloric stenosis. In addition, maternal use of macrolides during the first two weeks after birth was also associated with an increased risk of hypertrophic pyloric stenosis. A possible association was also found with use during late pregnancy (Marie et al., 2014). There is an increased risk of cerebral palsy or epilepsy associated with macrolide prescribing in pregnancy adds to evidence that macrolide use is associated with serious harm (Wilhelmine et al., 2015).

\section{Material and Methods}

\subsection{Drug}

Azithromycin is a white crystalline powder which is insoluble in water. It was obtained as a pure sample from purchased from pfizer co, Cairo, Egypt, and was suspended in water using few drops of Tween 80 .

\subsection{Animals}

Adult female Sprague-Dawley rats, 11-13 weeks, were used in the current study. They were got from the breeding colony then maintained at the animal house of the National Organization for Drug Control and Research (NODCAR, Giza, Egypt). Animals were caged in four groups, given suitable food and water was allowed 
ad libitum. Animals were subjected to an adaptation period of 2 weeks in the animal house before experiments. They were maintained at $21-24^{\circ} \mathrm{C}$ and $40-60 \%$ relative humidity with 12 -h lightdark cycle. Experimental procedures were conducted in accordance with the ethical guidelines for investigations in laboratory animals and were approved by the Research Ethical Committee of Faculty of Pharmacy, Cairo University (Cairo, Egypt) to comply with the Guide for the Care and Use of Laboratory Animals (Institute of Laboratory Animal Resources 1996). Vaginal smears were prepared every morning and examined under the light microscope for 5 days to select the female with regular estrus. Each two females were paired with a male of proven fertility in a separate cage overnight. In the next morning, a vaginal smear was taken to confirm the first day of pregnancy. Presence of spermatozoa in the obtained vaginal smear indicates day zero of pregnancy according to (Barcellona et al., 1977)

\subsection{Experimental design and sampling}

Pregnant rats $(n=40)$ were randomly divided into four groups (20 pregnant rats in treatment groups, 20 pregnant rats in the control and control tween 80 groups). The experimental groups were as follows: Group 1(control group) received the ordinary drinking water was used as the control solution; Group 2 (tween 80 group) received $1 \mathrm{ml}$ of $2 \%$ Tween 80 as a vehicle; Group3 received Azithromycin in dose $90 \mathrm{mg} / \mathrm{kg}$ b.wt and Group4 received Azithromycin in dose $180 \mathrm{mg} / \mathrm{kg}$ b.wt; modified human dose (Paget et al., 1964).The doses of drug in the treatment Groups was defined according to the weights of the rats. Moreover, the drug dose was adjusted accordingly. The control solutions and drug were administered orally, daily from $6^{\text {th }}$ until $15^{\text {th }}$ day of gestation via gastric tube. Water and food were supplied ad libitum during all the experiment.

\subsection{Developmental observations}

At the $20^{\text {th }}$ day of gestation female were sacrificed. Abortion, fetal resorptions, fetal body weight, body length and external malformation were recorded.

\subsection{Visceral examination}

The preserved fetuses in Bouin's fixative solution were rinsed with cold water andexamined grossly using magnifying lens. Several transverse sections were made throughout the fetal body (Hayes et al., 1986). All sections were examined on both sides under a dissecting microscope for any visceral malformations.

\subsection{Skeletal staining}

For skeletal examination, the other fetuses were examined for any skeletal abnormalities using alizarin red stain for fetal bone and alcian blue for cartilage (Inouye et al., 1976).

\subsection{Oxidative stress investigation}

Autopsy samples were taken from the liver of fetuses in different groups were stored at $-40^{\circ} \mathrm{C}$ for oxidative stress investigation. Piece of liver were weighted and homogenized in $10 \mathrm{mmol} / \mathrm{L}$ phosphate buffer saline (PBS) as $10 \%(\mathrm{~W} / \mathrm{V})$ at $\mathrm{pH}$ 7.4. The homogenates were centrifuged and the supernatants were taken for the estimation of Glutathione (GSH) reduced and malonaldahyde (MDA).

\subsubsection{Glutathione reduced (GSH)}

Tissue GSH was determined by calorimetric method using reagent kits obtained from Bio Diagnostic (Egypt) by the method of (Beutler et al., 1963).

\subsubsection{Malonaldahyde (MDA)}

Lipid peroxidation was determined in liver tissue homogenate by estimating the level of thiobarbituric acid reactive substances (TBARS) measured as MDA (Uchiyam et al., 1978).

\subsection{Histopathological preparation}

Liver and kidney of fetuses of different groups were fixed for histological examination by light microscopy in $10 \%$ formol saline for at least 24 hours and then preserved in $70 \%$ ethyl alcohol. Serial transverse sections 5 microns thick of different fetuses' tissues were cut mounted and stained with haematoxylin and eosin for general histological studies.

\subsection{Statistical analysis}

Results were expressed as mean \pm standard errors of the means (S.E.M). Statistical analysis was performed using the SPSS version 16 (Chicago, IL, USA), while the graphs were drawn using a prism computer program (Graph Pad software Inc. V5, San Diego, CA, USA). Statistical analysis was carried out using t- testes followed by unpaired Test. Probability values of less than 0.05 were considered statistically significant.

\section{Results}

\subsection{Effects of azithromycin on albino rat's foetuses dur- ing gestation}

\subsubsection{Abortion and resorptions}

Oral administration of Azithromycin in doses of 90 and 180 $\mathrm{mg} / \mathrm{kg} \mathrm{b}$.wt.) to pregnant rats from the sixth to the $15^{\text {th }}$ day of gestation caused abortion and early fetal resorptions (Table 1-2).

Table 1: Effect of Azithromycin ( 90.0 and $180.0 \mathrm{Mg} / \mathrm{Kg} \mathrm{B.Wt}$.) on the Abortion Percent

\begin{tabular}{lcccc}
\hline Groups & Doses $(\mathrm{mg} / \mathrm{kg} \mathrm{b}$.wt) & No. of used female & No. of abortion & Abortion(\%) \\
\hline Control & $1 \mathrm{ml}$ water & 10 & 0 & 0 \\
Control tween & $1 \mathrm{ml}$ tween & 10 & 0 & 0 \\
Azithromycin & 90 & 10 & 4 & 40 \\
& 180 & 10 & 2 & 20 \\
\hline
\end{tabular}

Table 2: Effect of Azithromycin ( 90.0 and $180.0 \mathrm{Mg} / \mathrm{Kg} \mathrm{B.Wt}$ ) on the Resorption Percent

\begin{tabular}{|c|c|c|c|c|c|c|c|}
\hline \multirow{2}{*}{ Groups } & \multirow{2}{*}{$\operatorname{Doses}(\mathrm{mg} / \mathrm{kg} \mathrm{b} . \mathrm{wt})$} & \multirow{2}{*}{ Number of sacrificed rats } & \multirow{2}{*}{ Number of Implantation sites } & \multicolumn{2}{|c|}{ Viablefetuses } & \multicolumn{2}{|c|}{ Resorbedfetuses } \\
\hline & & & & No. & $\%$ & No. & $\%$ \\
\hline Normal Control & $1 \mathrm{ml}$ water & 10 & 61 & 61 & 100 & 0 & 0 \\
\hline Control tween 80 & $1 \mathrm{ml}$ tween & 10 & 66 & 66 & 100 & 0 & 0 \\
\hline Arithromyin & 90.0 & 6 & 53 & 50 & 94.3 & 3 & 5.55 \\
\hline Azithromycin & 180 & 8 & 56 & 54 & 96.4 & 2 & 3.57 \\
\hline
\end{tabular}




\subsection{External morphological studies}

\subsubsection{Growth retardation and morphological abnormalities}

The morphological examination of the fetuses maternally treated from the sixth to the $15^{\text {th }}$ day of gestation with 90.0 and 180.0 $\mathrm{mg} / \mathrm{kg}$ azithromycin showed growth retardation represented by a decrease in fetal body weight and body length compared with the control groups. Oral administration of Azithromycin in doses of 90.0 and $180.0 \mathrm{mg} / \mathrm{kg} \mathrm{b}$.wt to pregnant rats from the $6^{\text {th }}$ to the $15^{\text {th }}$ day of gestation caused hematoma by percent 20.4 and $18.5 \%$ respectively when compared to zero percentage of the control group and $4.5 \%$ of the control tween 80 group. Also caused paralysis of limbs in 4.08 and $12.9 \%$ respectively when compared to zero percentage of the normal control and control tween 80 groups. Caused contraction of limbs in 0 and $5.55 \%$ respectively when compared to zero percentage of the normal control and control tween 80 groups (Fig. 1).

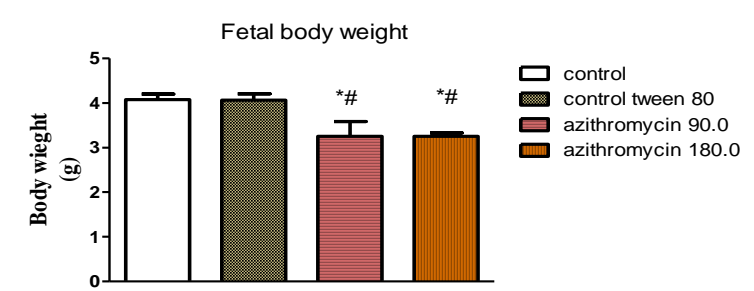

A

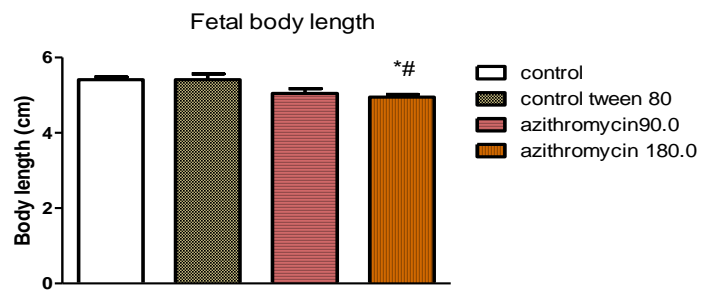

B

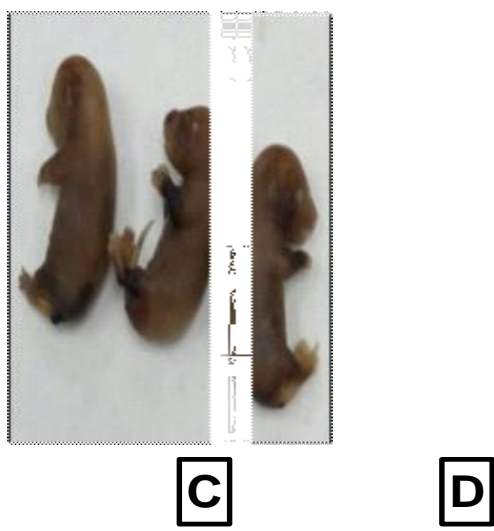

Fig. 1: A Histogram Showing Effect of Azithromycin on the Change in Fetal Body Weight (g)

of fetuses maternally treated with 90.0 and $180 \mathrm{mg} / \mathrm{kg}$ from $6^{\text {th }}$ to $15^{\text {th }}$ day of gestation (A) and on the change in fetal body length $(\mathrm{cm})$ of fetuses maternally treated with 90.0 and $180 \mathrm{mg} / \mathrm{kg}$ from $6^{\text {th }}$ to $15^{\text {th }}$ day of gestation (B) and photograph of fetuses obtained from pregnant rats given Azithromycin at $180 \mathrm{mg} / \mathrm{kg}$ b.wt from the $6^{\text {th }}$ to the $15^{\text {th }}$ day of gestation showing hematoma on all over the body $(\mathrm{C})$, and fetus obtained from pregnant rats given Azithromycin at $90.0 \mathrm{mg} / \mathrm{kg} \mathrm{b}$.wt from the $6^{\text {th }}$ to the $15^{\text {th }}$ day of gestation showing paralysis in two fore limb (D).

Data are expressed as mean \pm standard error of mean $(\mathrm{N}=6)$. The statistical differences were analyzed by ANOVA. *Significantly different from control and \#significantly different from control tween 80 at $\mathrm{p}<0.05$.

\subsection{Visceral examination of foetuses}

Concerning visceral examination, doses of 90.0 and $180.0 \mathrm{mg} / \mathrm{kg}$ b.wt. Of Azithromycin revealed cerebral dilatation in 36.36 and $33.33 \%$ of the examined fetuses, respectively as compared to $9.09 \%$ of the control group and $10 \%$ of control tween 80 group. This drug also produced microcephaly, the percentages of this abnormality were 27.2 and $11.11 \%$ of the examined fetuses, respectively as compared to $0 \%$ of the normal control and control tween 80 groups. .Azithromycin at $90.0 \mathrm{mg} / \mathrm{kg}$ b.wt.caused perforation of hard palate in $9.09 \%$ of examined fetuses when compared to $0 \%$ of the control and control tween 80 groups but Azithromycin at $180.0 \mathrm{mg} / \mathrm{kg}$ b.wt caused hemorrhage around internal organs by percent $22.22 \%$ as compared to $9.09 \%$ of the normal control group and $10 \%$ of control tween 80 group (fig 2.).

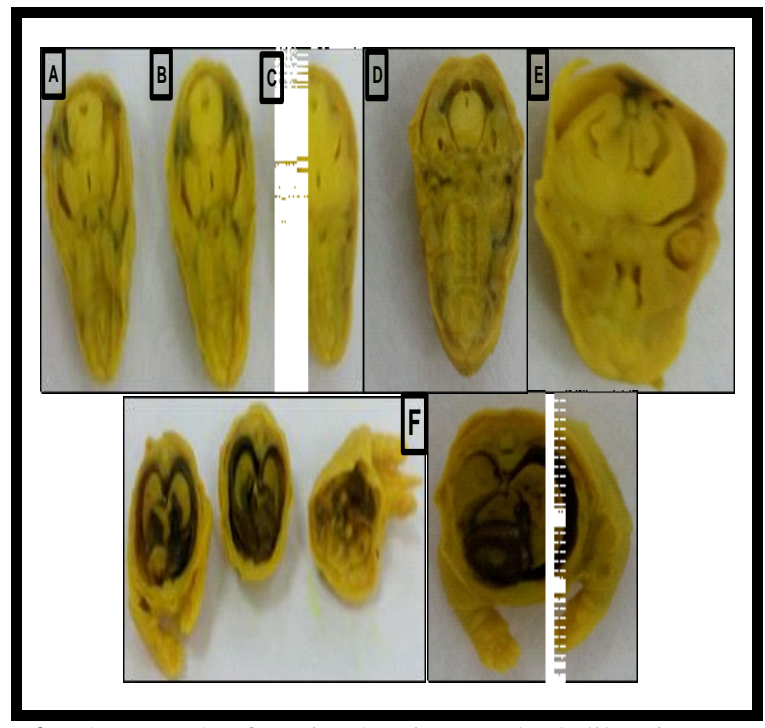

Fig. 2: Photograph of Brain showing cerebral dilatation (c), microcephaly (D), and perforated hard palate (E) in fetuses obtained from pregnant rats given $90.0 \mathrm{mg} / \mathrm{kg}$ b.wt. Azithromycin from the $6^{\text {th }}$ to the $15^{\text {th }}$ day of gestation, when compared to normal control and tween 80 control groups (A, B). In addition, hemorrhage all over the internal organs of fetuses obtained from pregnant rats given $180.0 \mathrm{mg} / \mathrm{kg} \mathrm{b} . w \mathrm{t}$. Azithromycin from the $6^{\text {th }}$ to the $15^{\text {th }}$ day of gestation (D). 


\subsection{Skeletal examination}

The skeletal system of control fetuses at the 20th day of gestation showed numerous bony elements stained with alizarin red and few cartilages stained with alcian blue. The main difference between control and maternally treated fetuses is the incomplete ossification of some bones in maternally treated groups. Concerning skeletal examination of alizarin red and alcian blue stained fetuses, the doses of azithromycin 90.0 and $180.0 \mathrm{mg}$. $\mathrm{kg}$ b.wt resulted in an incomplete ossification of the skull bones by $50 \%$ and $40 \%$ respectively. The percentages of lack of ossification of vertebral column in 16.6 and $40 \%$ respectively with the tested doses. Incomplete ossification of ribs was also reported by 16.6 and $40 \%$ respectively. Fetal skeletons of maternally treated rats with doses of azithromycin 90.0 and $180.0 \mathrm{mg}$. kg b.wt showed incomplete ossification fore limb bones by 16.6 and $20 \%$ of the examined fetuses respectively and incomplete ossification of hind limb bones by 33.3 and $95.0 \%$ respectively (Fig.3).

\subsection{Oxidative stress observations}

Lipid peroxidase (Malonaldahyde MDA) is significantly increased in fetus obtained from pregnant rat given Azithromycin at 90.00 and $180.00 \mathrm{mg} / \mathrm{kg}$ b.wt. from the $6^{\text {th }}$ to the $15^{\text {th }}$ day of gestation when compared to normal control and control tween 80 groups while Reduced glutathione is significantly decreased in fetus obtained from pregnant rat given Azithromycin by the same pattern when compared to normal control and control tween 80 groups. (Fig 4)

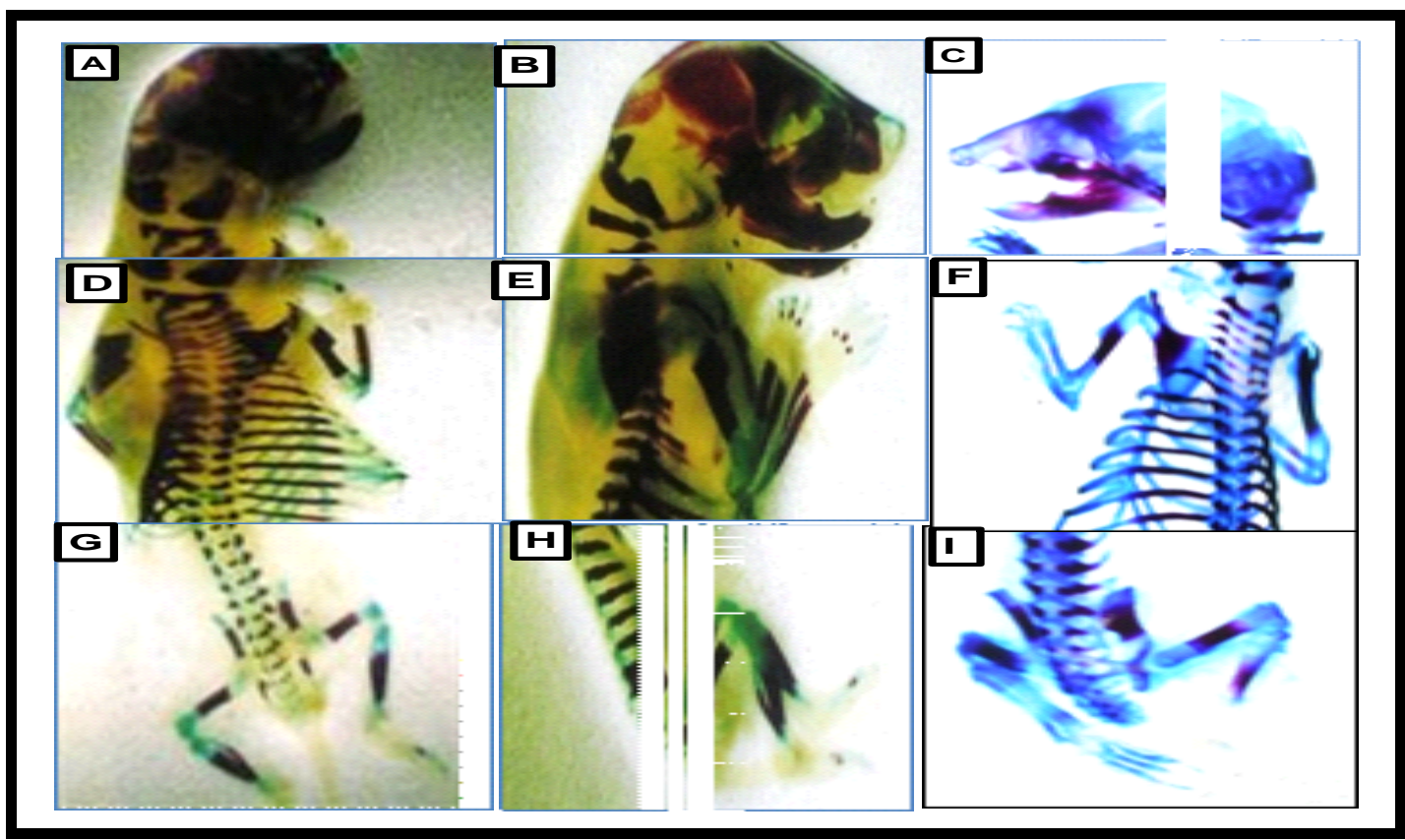

Fig. 3: Photograph of Head of Normal Rat Fetus. (A), control tween 80 fetus (B), and of fetus obtained from pregnant rat given $90.0 \mathrm{mg} / \mathrm{kg}$ b.wt. Azithromycin from the $6^{\text {th }}$ to the $15^{\text {th }}$ day of gestation showing lack of ossification of head bones (C). Photograph of fore limbs of normal rat fetus (D), of control tween 80 fetus (E), and of fetus obtained from pregnant rat given $90.0 \mathrm{mg} / \mathrm{kg}$ b.wt. Azithromycin from the $6^{\text {th }}$ to the $15^{\text {th }}$ day of gestation showing lack of ossification of radius, ulna, carpal and metacarpal bones (F). Photograph of hind limbs of normal rat fetus $(\mathrm{G})$, of control tween 80 fetus $(\mathrm{H})$, and of fetus obtained from pregnant rat given $180.0 \mathrm{mg} / \mathrm{kg}$ b.wt. Azithromycin during period of organogenesis showing lack of ossification of central of tibia ,fibula tarsal and metatarsl bone ( I).

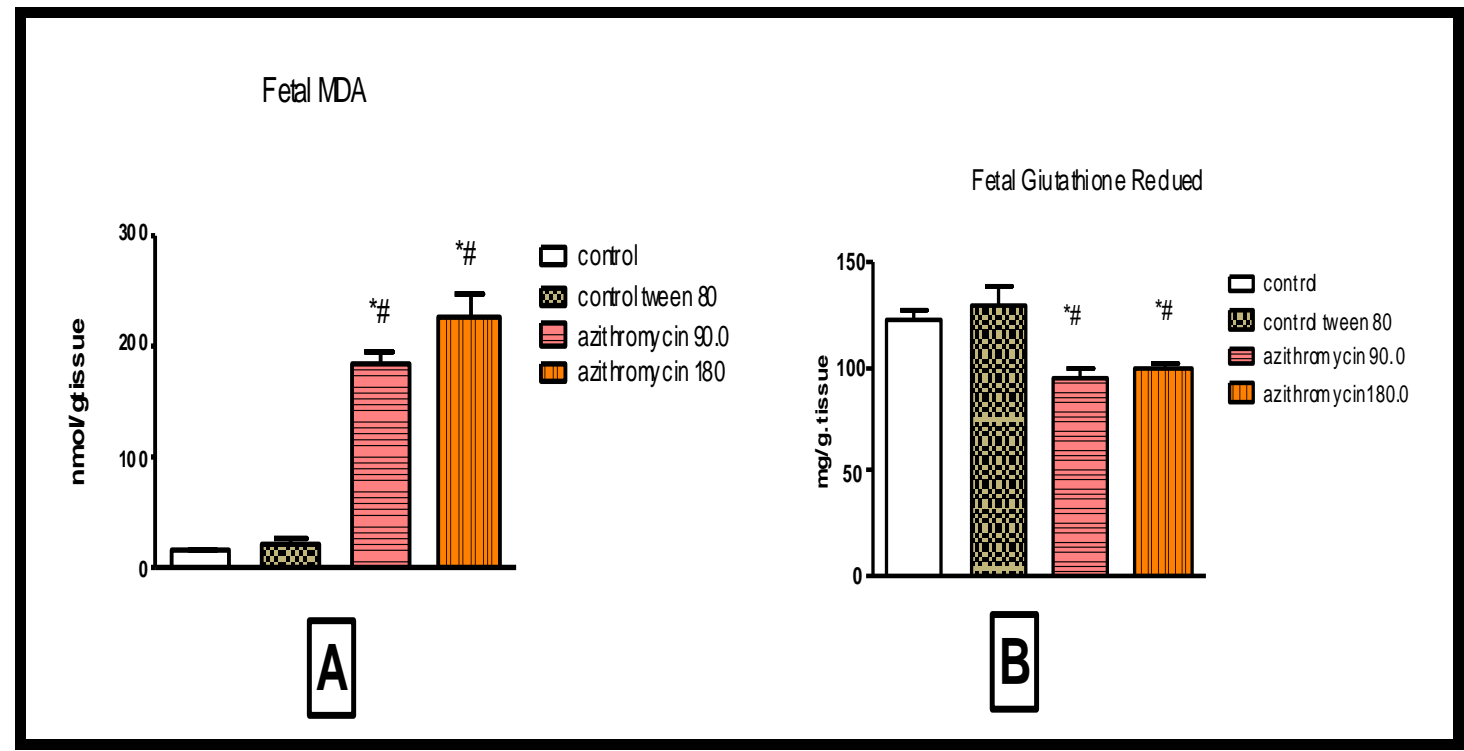

Fig. 4: Histogram Showing Effect of Azithromycin on Malonaldahyde (MDA) (A) and glutathione (GSH) (B) of fetuses maternally treated with 90.0 and $180 \mathrm{mg} / \mathrm{kg}$ from 6th to 15 th day of gestation. Data are expressed as mean \pm standard error of mean $(\mathrm{n}=6)$. The statistical differences were analyzed by ANOVA. *Significantly different from control and \#significantly different from control tween 80 at $\mathrm{p}<0.05$. 
(A) And glutathione (GSH) (B) of fetuses maternally treated with 90.0 and $180 \mathrm{mg} / \mathrm{kg}$ from $6^{\text {th }}$ to 15 th day of gestation. Data are expressed as mean \pm standard error of mean $(\mathrm{N}=6)$. The statistical differences were analyzed by ANOVA. *Significantly different from control and \#significantly different from control tween 80 at $\mathrm{p}<0.05$

\subsection{Histopathological studies}

Both different doses of azithromycin ( 90.0 and $180.0 \mathrm{mg} / \mathrm{kg}$ b.wt.) showed normal histopathological appearance in liver of fetuses'. However, Azithromycin at $90.00 \mathrm{mg} / \mathrm{kg}$ b.wt. Caused degeneration and necrosis in the tubular lining epithelium of kidney of fetuses from pregnant female administered it from day $6^{\text {th }}$ to day $15^{\text {th }}$ of pregnancy. Also azithromycin at $180.00 \mathrm{mg} / \mathrm{kg}$ b.wt caused fibrosis in between the atrophied renal tubules. (Fig 5)

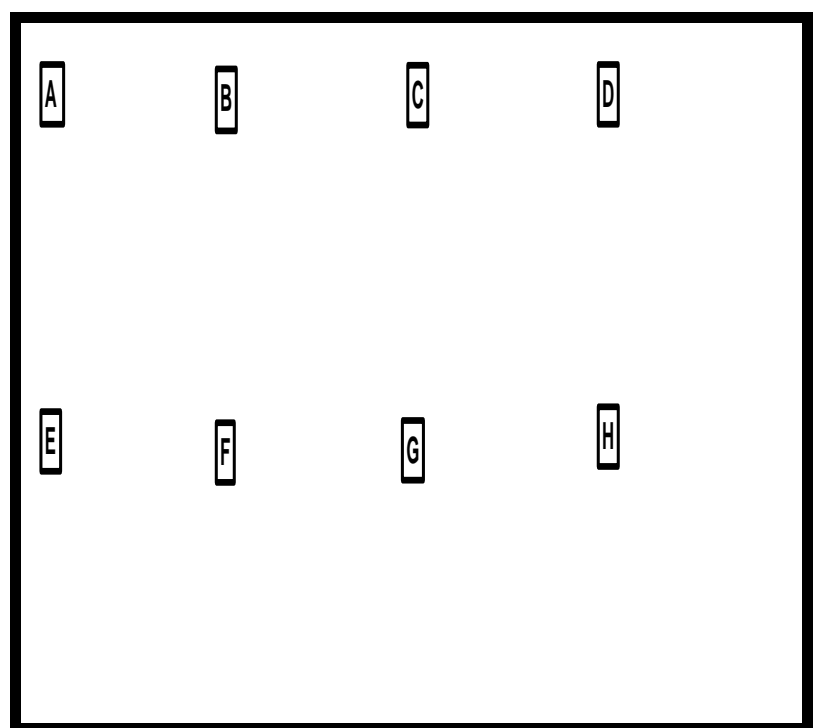

Fig. 5: Photograph of Liver of Fetus from Female Received Normal saline showing no histopathological alteration and the normal histological structure of the central vein and surrounding hepatocytes in the parenchyma (A), of fetus from female received tween 80 showing no histopathological alteration (B), of fetus from female received Azithromycin at $90.0 \mathrm{mg} / \mathrm{kg}$ b.wt. showing no histopathological alteration and the normal histological structure of the central vein and surrounding hepatocytes in the parenchy$\mathrm{ma}(\mathrm{C})$ and of fetus from female received Azithromycin at 180 $\mathrm{mg} / \mathrm{kg}$ b.wt. showing no histopathological alteration and the normal histological structure of the central vein and surrounding hepatocytes in the parenchyma (D) and of kidney of fetus from female received normal saline showing no histopathological alteration and the normal histological structure of the glomeruli and tubules at the cortex (E), of fetus from female received tween 80 showing no histopathological alteration the normal histological structure of the glomeruli and tubules at the cortex were recorded in $(\mathrm{F})$, of kidney of fetus from female received Azithromycin at $90.0 \mathrm{mg} / \mathrm{kg}$ b.wt. Showing degeneration and necrosis in the tubular lining epithelium $(\mathrm{G})$ and of kidney of fetus from female received Azithromycin at $180 \mathrm{mg} / \mathrm{kg}$ b.wt. showing Fibrosis in between the atrophied renal tubules $(\mathrm{H})$.

\section{Discussion}

Oral administration of azithromycin to pregnant rats increased the rate of abortion and the number of resorption sites. These findings received a marked support from another study, which concluded that a new macrolides azithromycin caused Elective terminations of pregnancy (Marie et al., 2014). In addition, administration of clarithromycin (macrolide antibiotic) from $15^{\text {th }}$ to $19^{\text {th }}$ days caused increase in the rate of abortion and resorptions (Gabri et al., 2015).
Azithromycin decreased the body weight and crown-rump length of exmined fetuses as compared to the control groups, an effect that is in line with a previous study as addition of spiramycin, azithromycin and clarithromycin decreased all growth and developmental parameters of rat embryos cultured in vitro in a dose dependent manner (Karabulut et al., 2008 ) also administration of clarithromycin and tilmicosin (a macrolide antibiotics) caused growth retardation of fetuses (Gabri et al., 2015 and Abo-Kora et al., 2016).

In the present work hematoma were seen in the examined fetuses obtained from pregnant rats treated with azithromycin. Similar results were seen in previous study (Karabulut et al., 2008). Azithromycin revealed cerebral dilatation, microcephaly, and perforation of hard palate and caused hemorrhage around internal organs. These results were previously seen as azithromycin caused neural tube defects, maxillary deformity and situs inverses (Karabulut et al., 2008). It was concluded that exposure to erythromycin or macrolides in the first trimester of pregnancy was associated with fetal cardiovascular or other malformations (Maria et al., 2012). Also tilmicosin caused some visceral defects (Abo-Kora et al., 2016). In this study Azithromycin caused an incomplete ossification of the skull bones, vertebral column bones, ribs, fore limb bones and hind limb bones. The obtained results were partially in agreement with obtained results of another macrolide, clarithromycin which cause severe lack of ossification on the skull bones, phalanges and sternum bone as well as shortness in the ulna and radius bones (Gabri et al., 2015) and that of tilmicosin which caused some skeletal defects (Abo-Kora et al., 2016).

In biochemical study; Lipid peroxidase is significantly increased in fetus obtained from females treated with Azithromycin but reduced glutathione is significantly decreased, previously Erythromycin caused significant increase in MDA and decreased in GSH concentration in pups' liver tissue in both gestation and lactation period (Preeti et al., 2014). There is relationship between Intra-uterine growth retardation (IUGR) and the antioxidant status, Level of lipid peroxidation was significantly higher in the IUGR group but the antioxidant enzyme activities and the levels of antioxidants were significantly lower in the IUGR group (Zsuzsanna et al., 2008).

The drug caused degeneration and necrosis in the tubular lining epithelium of kidney of fetuses and caused fibrosis in between the atrophied renal tubules. Same results obtained, as some chronic findings with liver histopathological examination of fetuses from females treated with erythromycin (Preeti et al., 2014). Clarithromycin administration to pregnant rats showed different histopathological changes in the kidneys of their fetuses. Administration of the antimicrobial agent; clarithromycin at early and late gestational period's exhibits nephrotoxicity in the developing fetuses (Farrag et al., 2015).

\section{Acknowledgment}

The authors would like to thank Prof. Adel Bakear (Pathology Department, Faculty of Veterinary Medicine, Cairo University, Cairo, Egypt, for their assistance in the histopathological examinations.

\section{Conflict of interest}

The authors declare that they have no financial or personal conflicts of interest that influenced or could be perceived to have influenced this work.

\section{References}

[1] Abo-Kora S, El-Meleh A, Aboubakr M. (2016) Effect of Tilmicosin on Fetal Developments in Pregnant Female Albino Rats. Pharma$\begin{array}{llll}\text { cology } \quad \& \quad \text { Pharmacy. } & 7(4)\end{array}$ 4236.https://doi.org/10.4236/pp.2016.74019. 
[2] Aboubakr M, Elbadawy M, Soliman A, and El-Hewaity M. (2014) Embryotoxic and Teratogenic Effects of Norfloxacin in Pregnant Female Albino Rats. Advances in Pharmacological Sciences. doi:10.1155/2014/924706. https://doi.org/10.1155/2014/924706

[3] Barcellona, P.S.; Fancelli, O.; and Campana, A. (1977) Teratological study of etoperidone in the rat and rabbit. Toxicol. Eight: 8794.https://doi.org/10.1016/0300-483X(77)90026-9.

[4] Benjamin,B.; Orna, D.; Svetlana, S.; Rotem,T.;Judith, A.;Igor, F.; Matitiahu, B.; and Asher, O. (2008) Pregnancy outcome after gestational exposure to the new macrolides:A prospective multi-center observational study. Euro. J. ObstretGynecolReprodBiol.141; 31 34https://doi.org/10.1016/j.ejogrb.2008.07.008.

[5] Beutler, E.; Duron, O.; and Kelly, B.M. (1963) Improved method for the determination of blood glutathione. J Lab Clin Med. 61:8828.

[6] Brent, R. L., \& Fawcett, L. B. (2007) Developmental toxicology, drugs and fetal teratogenesis. Clinical Obstetrics. 261.

[7] Elkomy A, Aboubakr M and Medhat N. (2016) some teratologica effects of difloxacin in rats. Benha Veterinary Medical Journal. 30(1): 266-271.

[8] Elsayed M, Elkomy A, Aboubakr M, and Morad M. (2014) Tissue Residues, Hematological and Biochemical Effects of Tilmicosin in Broiler Chicken. Veterinary Medicine International. doi:10.1155/2014/502872.https://doi.org/10.1155/2014/502872.

[9] Farrag, AH,Hassan, BN, Ezz-Eldin D, Gabri MS, Kandil, AM. (2015) Histological and Immunohistochemical Studies on the Kidneys of Pregnant Rats Treated with Clarithromycin. The Egyptian Journal of Hospital Medicine.61:591 614.https://doi.org/10.12816/0018763.

[10] Gabri, M.S.;Asmaa,M. K.;Maiada, M.;andNehad, M. (2015) Effect of clarithromycin administration during late gestational period on the pregnant albino rats and their fetuses.The Egyptian Journal of Hospital Medicine. 60.

[11] Hayes, A.W. (1986) Principles and Methods of Toxicology. Student Edition, Raven Press, New York, 141-184.

[12] Hracsko Z, Orvos H, Novak Z, Pal A, Varga IS. (2008) Evaluation of oxidative markers in neonates with intra uterinr growth retardation. Redox Report. 13:11 16.https://doi.org/10.1179/135100008X259097.

[13] Inouye, M. (1976) Differential staining of cartilage and bone in fetal mouse skeleton by Alcianblue and Alizarin red-Congenital Anomalies. 16: 171-173.

[14] Institute of Laboratory Animal Resources (1996) Guide for the Care and Use of Laboratory Animals, 8th edition. Washington, D.C.: National Academy Press.

[15] Karabulut, A .K. Uysa, I. I.; Acar, H.; and Fazliogullari,H.(2008) Investigation of developmental toxicity and teratogenicity of macrolide antibiotics in cultured rat embryos. Anat. Histol. Embryol. 37 369-375https://doi.org/10.1111/j.1439-0264.2008.00861.x.

[16] Koren, G.; Pastuszak, A.; and Ito, S. (1998) Drugs in pregnancy. N
Engl
Med.
338:

https://doi.org/10.1056/NEJM199804163381607.

[17] Maria, R.; Morten, L; and Hedvig, N. (2012) Pregnancy outcome after gestational exposure to erythromycin - a population-based register study from Norway.British Journal of Clinical Pharmacology. $\quad$ 74: 1053-1062.https://doi.org/10.1111/j.13652125.2012.04286.x.

[18] Marie, L; Björn, P. P.; Rie, BS.; Bjarke F.; Camilla K.; Lars J Diaz .; Jan Wohlfahrt chief .; and Mads Melbye . (2014) Use of macrolides in mother and child and risk of infantile hypertrophic pyloric stenosis: nationwide cohort study. BMJ; 348 1908.https://doi.org/10.1136/bmj.g1908.

[19] Paget, G.E. and Barnes, I.M. (1964) Interspecies dosage conversion scheme in evaluation of results and quantitative application in different species in (evaluation of drug activities: Pharmacometrics), Laurance, D.R. and Bachorach, A.L. (Edrs), Academic Press London and New York.; 1: 160-163.

[20] Preeti,S.; Lubhan,S.; Sambhu,C. M.; Sokindra, K.; and Ishwari N.S (2014) Erythromycin induced genotoxicity and hepatotoxicity in mice pups Treated during post gestation period. Fundamental and clinical pharmacology; 28: 519529.https://doi.org/10.1111/fcp.12055.

[21] Ramsey, P.S.; Vaules, M.B.; Vasdev, G.M.; Andrews,W.W ; and Ramin ,K.D. (2003) Maternal and transplacental pharmacokinetics of azithromycin. Am J Obstret Gynecol. 188:714 718?https://doi.org/10.1067/mob.2003.141.

[22] Uchiyama M and Mihara M. (1978) Analytical biochemistry. 86 271https://doi.org/10.1016/0003-2697(78)90342-1.

[23] Meeraus WH, Petersen I, Gilbert R. (2015) Association between Antibiotic Prescribing in Pregnancy and CerebralPalsy or Epilepsy in Children Born at Term: A Cohort Study Using TheHealth Improvement Network. 